\title{
Contribuições Psicanalíticas Acerca da Violência Conjugal
}

Psychoanalytic Contributions on Marital Violence

Contribuciones Psicoanaliticas Sobre la Violencia Conygal

Suzana Catanio dos Santos Nardi

\& Silvia Pereira da Cruz Benetti

Universidade do Vale do Rio dos Sinos

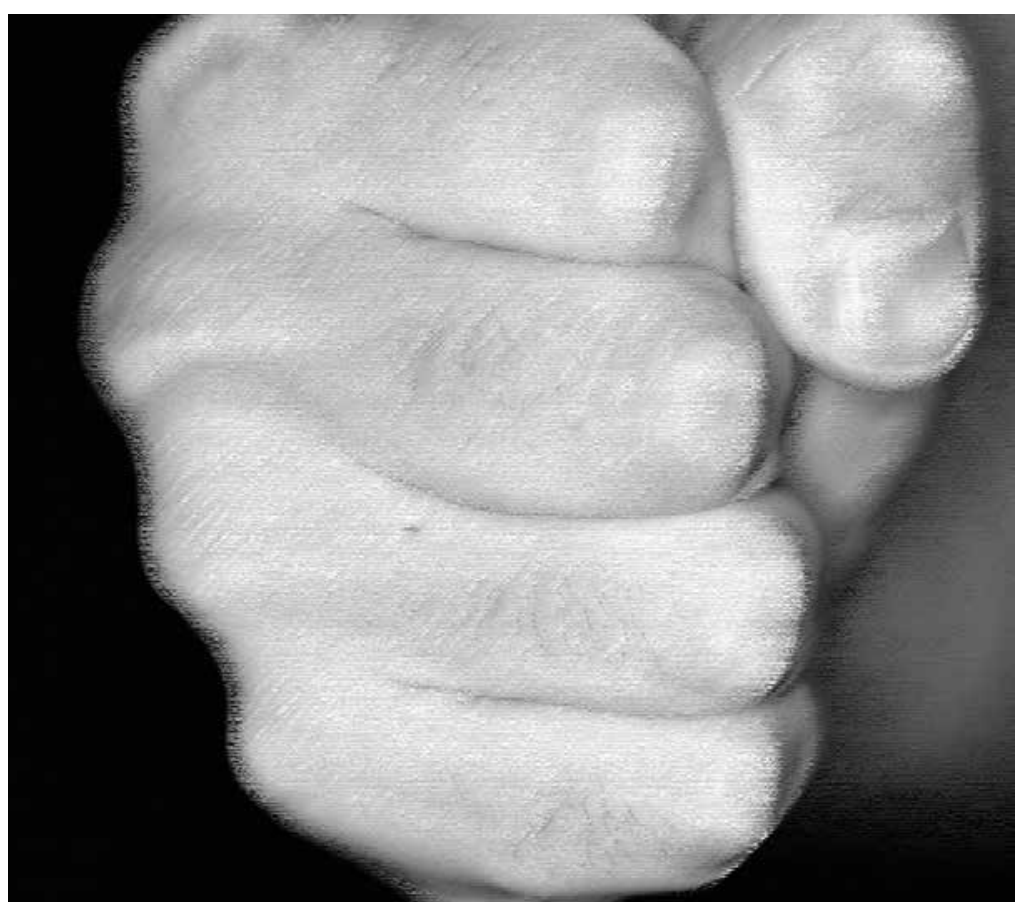


Resumo: A violência é uma questão que há muito tempo vem despertando a atenção de estudiosos. Assim, a temática da agressividade humana e dos aspectos psíquicos associados aos impulsos agressivos tem sido extensamente abordada como objeto de estudo da teoria psicanalítica. O presente artigo se propõe apresentar algumas contribuições psicanalíticas acerca da violência. Para isso, autores clássicos como Freud e Klein, passando pela teoria do apego, com Bolwby, e contemporâneos como Kernberg e Fonagy, são considerados neste trabalho. Observa-se que a psicanálise tem feito um percurso na tentativa de compreender o funcionamento psíquico de indivíduo violento, constituindo-se um referencial que pode oferecer subsídios interessantes para uma identificação mais aprofundada dos aspectos intrapsíquicos envolvidos na agressão.

Palavras-chave: Psicanálise. Relações de objeto. Teoria do apego. Violência.

Abstract: Violence is a matter that has been present in researchers' interest for a long time. Therefore, the themes of human aggressiveness and of the psychological aspects associated to the aggressive impulses have been object of study of the psychoanalytic theory. The present article intends to present some psychoanalytic contributions on the theme of violence. This way, classic authors such as Freud and Klein, including Bolwby's attachment theory and contemporaries authors like Kernberg and Fonagy are considered in this work. It is noticed that psychoanalysis has trodden a long way in the attempt of understanding the psychological functioning of the violent individual, constituting a referential system that can offer interesting subsidies for the identification of the intrapsychic aspects involved in aggression.

Keywords: Psychoanalysis. Object relations. Attachment behavior. Violence.

Resumen: La violencia es un tema que ha despertado mucho la atención de los estudiosos. Por lo tanto, el tema de la agresión humana e los aspectos psicológicos asociados con los impulsos agresivos han sido ampliamente discutido como un objeto de estúdio en la teoría psicoanalítica. En este trabajo se propone presentar algunas aportaciones psicoanalíticas sobre la violência. Para ello, los autores clásicos, como Freud y Klein, a través de la teoria del apego, con Bolwby y contemporáreos tales como Kernberg y Fonagy, se consideran em este trabajo. Se observa que el psicaoanálisis ha hecho un curso em un intento de comprender el funcionamiento psicológico de la persona violeta, convirtiéndose en una referencia que puede proporcionar información interessante para su posterior identificación de los aspectos intrapsíquicos involucrados en el ataque.

Palabras-clave: Psicoanálisis. Relaciones de objeto. Conducta del apego. Violencia.

O campo teórico da psicanálise tem contribuído com importantes aportes conceituais para a compreensão dos aspectos intrapsíquicos da violência e da agressão (Freud, 1920/1976, 1924/1976, 1930/1996; Klein, 1932/1969; Kernberg, 1995; Kernberg, Yeomans, Clarkin, \& Levy, 2008; Fonagy, 1999, 2000) bem como da própria associação entre a sublimação do ato agressivo e a formação da civilização (Freud, 1919/1996). Portanto, o conceito de agressão, sob o vértice psicanalítico, foi relacionada tanto a conceitos fundamentais do funcionamento psíquico individual quanto a aspectos mais amplos referentes ao processo de constituição e de desenvolvimento do processo civilizatório humano (Freud, 1919/1996, 1930/1996). Nesse sentido, Freud agregou ao fenômeno a perspectiva de que a agressão constitui um aspecto intrínseco da natureza humana, posição que gerou controvérsias. "Essa agressão cruel (...) desmascara os seres humanos como bestas selvagens que nem sequer respeitam os membros de sua própria espécie" (1930/1996, p. 108).

Ainda que a teoria psicanalítica tenha ampliado a compreensão dos fenômenos ligados à violência e à agressão, Cogan, Porcerelli e Dromgoole (2001) consideram que pouco tem sido feito em relação ao estudo específico dos indivíduos que cometem atos violentos. Sobretudo, observa-se que a contribuição psicanalítica tem se orientado para o trabalho clínico, principalmente para os aspectos estruturais da personalidade, localizando padrões agressivos de interação nas situações de funcionamento limítrofe ou 


\footnotetext{
Sobretudo, observa-se que a contribuição psicanalítica tem se orientado para o trabalho clínico, principalmente para os aspectos estruturais da personalidade, localizando padrões agressivos de interação nas situações de funcionamento limítrofe ou borderline (Kernberg, 1995).
}

borderline (Kernberg, 1995). Assim, o número de trabalhos dedicados à compreensão intrapsíquica de indivíduos violentos não é tão significativo, indicando uma área de estudo carente de investigações psicanalíticas voltadas para esse aspecto. Tal é o caso de estudos que envolvem agressores nas situações de violência conjugal, ou seja, casos em que exista violência entre parceiros no relacionamento de namoro ou de casamento, formalizado ou não.

Portanto, ainda que o enfoque clínico tenha contribuído de forma significativa para o avanço no atendimento de patologias, é fundamental uma compreensão mais aprofundada do funcionamento intrapsíquico do agressor nos casos de violência conjugal com destaque para os aspectos edípicos e para o papel das relações objetais estabelecidas ao longo do desenvolvimento, visto que essas vivências formam a base para os futuros relacionamentos, durante todo o ciclo vital.

Cogan et al. consideram a violência conjugal distinta dos atos violentos dirigidos a pessoas em geral, e associam esse tipo de violência a características específicas do funcionamento psíquico do agressor. Especificamente, destacam os elementos psíquicos ligados à ansiedade de castração e ao Édipo nas manifestações de violência conjugal. Nessa direção, em um estudo realizado com homens violentos com suas parceiras, com estranhos ou em ambos os casos (Cogan \& Porcerelli, 1996; Cogan et al., 2001), foi observado que as vulnerabilidades e as angústias dos homens em relações conjugais violentas são diferentes dos problemas dos homens violentos com outras pessoas. Assim, nesse estudo, identificou-se que a angústia de castração na violência entre parceiros foi mais intensa, enquanto o papel do álcool foi mais importante na violência contra estranhos. Em função dessas particularidades verificadas nos distintos grupos de homens violentos, os autores destacam a importante contribuição que a teoria psicanalítica pode oferecer para o estudo das características intrapsíquicas desses indivíduos, especialmente nas situações da violência conjugal.

Todavia, além das questões relativas à violência e ao gênero (Kronbauer \& Meneghel, 2005), em especial à questão feminina na sociedade (Saffioti, 2001), que certamente influenciam as manifestações violentas, acreditamos que o estudo aprofundado que vise à compreensão das singularidades das características psíquicas do homem agressor pode contribuir com elementos importantes para o desenvolvimento de intervenções dirigidas para distintas esferas de atenção, sejam elas em nível familiar, individual ou coletivo. Portanto, considerando a importância dessas questões, este artigo tem como objetivo discutir algumas das contribuições psicanalíticas sobre a violência conjugal, apresentando uma breve revisão do pensamento de Freud sobre a agressão humana e discutindo os modelos psicanalíticos contemporâneos derivados da perspectiva da teoria das relações objetais (Klein, 1932/1969; Kernberg, 1979) e da teoria do apego (Bowlby, 1969/1990, 1984; Fonagy, Gergely, Jurist, \& Target, 2002).

\section{Contribuições freudianas}

Em termos históricos, Freud (1905/1996) primeiramente tomou o impulso agressivo como a oposição entre a pulsão sexual e a pulsão de autoconservação, associando a agressão ao impulso sexual. Na primeira teoria pulsional, Freud (1920/1976) opõe o sexual e o autoconservativo, dando maior ênfase aos aspectos inerentes à pulsão sexual e destacando que as manifestações agressivas têm origem em distintas situações. 
Conforme Laplanche e Pontalis (2001), nessa etapa de sua obra, Freud não reconhecia a agressão como derivada de um impulso próprio, mas da relação entre a sexualidade e o instinto de autoconservação. Assim, no texto O Instinto e suas Vicissitudes (Freud, 1915/1996), são apresentados os destinos pulsionais ao longo do processo de desenvolvimento e no decorrer da vida, os quais incluem a reversão ao seu oposto, o retorno ao próprio eu, a repressão e a sublimação. A condição de reversão ao seu oposto pode dar-se no processo de transformação de atividade em passividade e na reversão de conteúdo. No primeiro caso, temos a transformação do sadismo em masoquismo, e, no segundo, a transformação de amor em ódio. Esse caso é uma situação única e indicativa da ambivalência dos impulsos.

Nessa direção, em Três Ensaios sobre a Teoria da Sexualidade, Freud (1905/1996) apresenta a noção de masoquismo como a brutalidade associada à pulsão sexual, a dor vinculada ao prazer e a existência simultânea tanto das formas passivas quanto das ativas no mesmo indivíduo. Assim, em determinadas situações extremas, a passividade está aliada à satisfação, associando-se ao sofrimento aplicado pelo objeto sexual.

Da mesma forma, o sadismo foi considerado por Freud (1924/1976) um componente da pulsão sexual, consistindo no emprego da violência ou da força sobre outra pessoa. Já em relação ao masoquismo, ele acreditava que o sentimento de culpa estava inconscientemente vinculado a esse componente. Assim, o sujeito esperava ser punido por alguma coisa de que, em sua fantasia, julga ser culpado, especialmente de situações ligadas à masturbação infantil.

Alem desses aspectos, Freud (1930/1996) introduz a ideia de que sadismo e masoquismo estavam associados ao instinto destrutivo e mesclados ao erotismo. $\mathrm{O}$ autor considera, portanto, que o instinto agressivo resulta da pulsão de morte, e que, ao lado de Eros, domina da mesma forma o mundo. Essa posição contrasta com a sua perspectiva inicial, quando, assim como outros psicanalistas, não se admitia a existência de uma pulsão de agressão, passando-se, posteriormente, à ideia de um dualismo pulsional. Assim, a agressividade foi considerada parte do conflito entre a pulsão de vida e a pulsão de morte.

Os elementos agressivos e hostis estão presentes no bebê ao nascer e são gradualmente limitados durante o desenvolvimento psíquico. Partindo de uma posição autoerótica e narcisista, quando o princípio do prazer demanda do objeto gratificação total, o gradual reconhecimento do outro restringe as manifestações e as ações agressivas dirigidas ao objeto. Nesse sentido, Ferrari (2006) destaca que a crueldade tem origem nos momentos pré-edípicos, quando ainda não prevalece o reconhecimento e a compaixão pelo outro, ocorrendo a passagem ao ato. Assim, para Freud, o sadismo infantil é associado à fase anal-sádica, na qual já se estabeleceu uma relação de objeto, ainda que pré-genital, o que implica uma característica autoerótica de satisfação libidinal ligada à expulsão e à retenção das fezes. Por sua vez, o momento edípico é entendido como um organizador dos impulsos agressivos na rivalidade em jogo pela posse parental. Entretanto, nesse momento evolutivo, podem ocorrer situações ligadas ao interjogo passivo/ ativo presentes nessa etapa.

A agressão ou a pulsão de morte como uma pulsão independente e oposta à sexualidade e à conservação, pulsão de vida, aparece em Além do Princípio do Prazer (Freud, 1920/1976). Dessa forma, tomando como referência as proposições psicanalíticas 


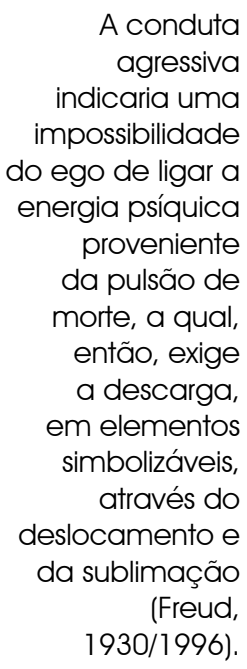

A conduta agressiva indicaria uma impossibilidade do ego de ligar a energia psíquica proveniente da pulsão de morte, a qual, então, exige a descarga, em elementos simbolizáveis, através do deslocamento e da sublimação (Freud, 1930/1996).

na perspectiva das últimas conceituações freudianas, o autor descreve que toda estrutura viva é formada por aspectos pulsionais: pulsão de vida (Eros) e pulsão de morte (Tânatos). A conduta agressiva indicaria uma impossibilidade do ego de ligar a energia psíquica proveniente da pulsão de morte, a qual, então, exige a descarga, em elementos simbolizáveis, através do deslocamento e da sublimação (Freud, 1930/1996).

A agressividade relaciona-se à motricidade impulsiva ou ao ato destrutivo que ocorre como resposta ao aumento de excitação, que é, então, descarregada. Ao contrário, a percepção desse aumento é vista como uma ameaça à própria organização psíquica, indicando que ocorreram falhas no aparelho psíquico para lidar com/simbolizar essas experiências (Freud, 1920/1976). O sujeito, então, seria intrinsecamente mau e destrutivo, sendo que a força da civilização se faz necessária para a contenção dos desejos, pois, de outra forma, estar-se-ia fadado a viver de maneira impulsiva, como os povos selvagens.

Anteriormente, em Totem e Tabu, Freud (1913/1976) já apresentara o tabu do incesto como o marco fundamental para o desenvolvimento da sociedade humana, logo, ampliando a importância desse conflito para o processo civilizatório. Assim, o medo do incesto e o impulso à exogamia foram entendidos como marcos de passagem de uma organização primitiva para o surgimento do indivíduo social. A morte do pai introduz a representação da lei em nível simbólico, pois seu lugar passa a ser o de um Pai mítico. Assim sendo, tal cena origina o fundamento da sociedade pela aceitação de normas e de leis que regem os impulsos humanos.

Dessa forma, a existência do sujeito, como ser humano e social, só se dá através de sua inserção no simbólico, que the garante a habilidade de estabelecer comunicação, relacionamentos com outros sujeitos e com o mundo que o rodeia. Em consequência, a cultura torna-se a própria condição de possibilidade do ser humano. Desse modo, o caminho que leva o homem para a cultura é o confronto entre a impotência e a onipotência e, portanto, o estabelecimento da lei, ocasião em que o sujeito se vê limitado, tendo a lei como norteadora e limitadora, o que possibilita a convivência em sociedade (Freud, 1913/1976).

A leitura da contribuição freudiana, a do modelo estrutural pulsional, permite que se identifique que o estudo da agressão humana forneceu conceitos centrais para a compreensão do desenvolvimento e do funcionamento psíquico sob a perspectiva intrapsíquica, bem como dos aspectos interrelacionais da formação social e cultural da civilização. Com base nesses conceitos, desenvolveram-se perspectivas teóricas importantes, com Klein, Ferenczi (1933/1992) e Winnicott (1960/1989), representantes do modelo estrutural relacional. No presente trabalho, são destacados os elementos relativos à teoria das relações objetais e à teoria do apego em interface com a questão da violência.

\section{Contribuições contemporâneas}

A partir de Freud, algumas contribuições psicanalíticas têm ampliado a compreensão dos processos relacionais envolvidos nas situações de violência (Kernberg, 1995; Fonagy et al., 2002; Schmidt-Hellerau, 2002), destacando em especial o papel das relações objetais internalizadas e das características do estilo de apego estabelecido na primeira infância. Os modelos compreensivos privilegiam principalmente o papel das características vinculares estabelecidas nos 
relacionamentos primitivos com as figuras parentais bem como as características das representações objetais derivadas dessas interações (Lamanno-Adamo, 1999).

Assim, tomando como base trabalhos ulteriores da psicanálise acerca do papel das relações com o objeto externo ao longo do desenvolvimento, na consolidação de uma representação psíquica de si mesmo (self) e do outro, incluindo, nesse processo, o papel das fantasias, das memórias e do afeto, foram sendo desenvolvidos modelos sobre a organização do aparelho psíquico e sobre sua influência na manutenção e na regulação pulsional (Schmidt-Hellerau, 2002; Kernberg et al., 2002).

Considerando especificamente a questão da violência doméstica, Lamanno-Adamo (1999) afirma que esses comportamentos violentos resultam de distorções psíquicas relativas a aspectos da realidade. Essas distorções originam-se em um ambiente que não auxilia o bebê na construção de um senso de pertencimento a um grupo familiar, o que não contribui para a discriminação dos fatos e das fantasias, propiciando o desenvolvimento de sujeitos com sentimentos frequentes de ameaças de desintegração do ego. Com base nessas experiências, constroem-se defesas psíquicas fundadas nos mecanismos da repressão e da negação, que permanecem organizadas e firmemente mantidas, utilizadas com o objetivo de manter o ego protegido do excesso de ansiedade. Nesse sentido, a autora destaca que a violência é manifestação em face do medo intenso associada a estruturas inconscientes.

\section{Teoria das relações objetais}

Utilizando especificamente o referencial da teoria das relações objetais, diversos estudos (Kernberg, 1995; Zosky, 1999;
Diamond, 2004) têm possibilitado maior compreensão do impacto das vivências traumáticas no desenvolvimento posterior de patologias acerca das situações de violência na vida adulta. Nesse caso, são destacadas as representações mentais do objeto relativas aos elementos vinculares estabelecidos ao longo do desenvolvimento, as quais serão determinantes da capacidade de simbolização dos impulsos agressivos.

A expressão relação de objeto, de acordo com Laplanche e Pontalis (2001), é utilizada de maneira frequente na psicanálise contemporânea para designar a maneira como o sujeito se relaciona com seu mundo, com base em uma organização de personalidade específica, na apreensão mais ou menos fantasiosa dos objetos e em determinados tipos de defesa.

Conforme Bruscato (1998), o termo relação objetal refere-se à habilidade dos indivíduos para os relacionamentos interpessoais, indicando as atitudes e os comportamentos em relação aos seus objetos, seja referindose aos indivíduos reais, seja a imagens mentais. O termo objeto é utilizado em relação a uma pessoa ou a algo concreto, real, porém externo, e que difere do sujeito. A representação objetal ou objeto interno contém as diversas qualidades do objeto externo. Desse modo, a relação objetal refere-se às representações intrapsíquicas das relações com os outros, relações essas que são inferidas com base nas experiências relatadas ou nas condutas observadas nos relacionamentos objetais (Moore \& Fine, 1990; Nigg et al., 1991), já que os objetos internos são representações intrapsíquicas das relações com outros indivíduos.

Para a teoria das relações objetais, a organização do aparelho psíquico origina-se na interação entre os aspectos intrapsíquicos 
Portanto, é a partir do reconhecimento das experiências próprias e das experiências dos demais, dos limites pessoais e das necessidades do outro que se estabelecem relações interpessoais com intimidade (Kernberg et al., 2008). e os objetos externos derivados do relacionamento com os outros. No decorrer das interações com esses objetos externos, ocorre a internalização do objeto e de suas características, permitindo que elementos do mundo externo e das interações passem a ser representados internamente. Esse processo é de fundamental importância para o desenvolvimento tanto da estrutura psíquica quanto da personalidade e do funcionamento mental (Moore \& Fine, 1990). Logo, a internalização dessas experiências é o principal colaborador primário para o desenvolvimento psicológico, pois, por meio dela, as estruturas mentais vão estabelecendose de maneira que o indivíduo gradualmente esteja capacitado a assumir as funções que, de início, eram preenchidas por outros.

Inicialmente, o bebê, sendo tão frágil, tanto no aspecto físico de cuidados quanto no aspecto emocional, é dependente da mãe ou de um cuidador. De modo gradual, durante a primeira infância, o bebê vai conhecendo frustrações, que são importantes para o seu desenvolvimento, para que ele possa adquirir a capacidade de tolerá-las. Porém, se forem excessivas, podem gerar intensos sentimentos de ódio, vivenciados como uma ameaça terrorífica à sobrevivência, sob a forma de terror de fragmentação. Dessa forma, o bebê lança mão de um mecanismo mental extremamente primitivo, quando coloca para fora de si os conteúdos agressivos, dos quais necessita livrar-se, pois não consegue percebê-los como algo próprio (Klein, 1932/1969).

Sobretudo, quando a mãe se encontra atormentada ou angustiada com as projeções de seu bebê, não conseguindo processar dentro de si tais projeções de raiva e angústia, a relação fica atravessada por sentimentos ambivalentes que provocam no bebê fantasias inconscientes de que é ele quem possui os elementos destrutivos, e o objeto de seu intenso ódio é o seio, que é possuidor de conteúdos extremamente maus, com intensa capacidade de destruição. $\mathrm{O}$ ego do bebê, nessa circunstância, não consegue desenvolver-se de maneira adequada, gerando a percepção distorcida de um mundo mau, sem habilidade de suportar suas angústias, seu ódio, ou ele próprio (Klein, 1932/1969).

Por outro lado, se houver vivências agradáveis, como acontece quando o bebê é amamentado, acarinhado, acolhido e olhado nos olhos, além de ouvir palavras afetuosas da mãe, ele tem experiências de um seio bom, gratificador, o que suscita a percepção de um mundo acolhedor, seguro, tranquilizante. Em consequência, desenvolvem-se defesas organizadas e firmemente mantidas. A repressão, a negação e a recusa são utilizadas com o objetivo de manter o ego protegido do excesso de ansiedade que ocorre devido à falha de assimilação de determinadas experiências. O bebê, desse modo, estrutura seu ego rudimentar e imaturo, utilizandose do ego auxiliar da mãe para organizá-lo e acalmá-lo, até que essas funções sejam interiorizadas por meio da maturação e da contínua internalização das representações (Maciel \& Rosemburg, 2006).

Essas experiências iniciais vão permitir, principalmente, o desenvolvimento gradual da capacidade de reconhecer-se separado do objeto e de identificar que o objeto tem características e vivências afetivas próprias. No adulto, tais experiências permitem uma organização interna autônoma do sujeito, com um senso de identidade própria bem como uma experiência pessoal com os demais rica e criativa. Portanto, é a partir do reconhecimento das experiências próprias e das experiências dos demais, dos limites pessoais e das necessidades do outro que se estabelecem relações interpessoais com intimidade (Kernberg et al., 2008). 
Alguns aspectos, ao contrário, se destacam nos padrões de interações violentas, tais como vivências associadas ao desenvolvimento psíquico com falhas na capacidade de tolerar a perda do objeto de amor, com elementos narcisistas preponderantes na estrutura de personalidade ou até situações de rivalidade edípica que provoquem ansiedades de castração (Zosky, 1999). Logo, adultos que experienciaram falhas no amparo adequado de suas necessidades e poucas representações positivas internalizadas das interações com os objetos primários apresentam dificuldades para acalmarem-se em momentos de ansiedade, para manter uma autoestima saudável e para regular as respostas emocionais ao mundo exterior. No caso do agressor, a possibilidade da perda do objeto amado é vivida por ele como perda total, de si mesmo, porque não possui as imagens internalizadas para a garantia de sua segurança (Kernberg, 1995).

Segundo Zosky, indivíduos que experienciaram violência doméstica na infância podem envolver-se em relacionamentos objetais com características patológicas, já que as experiências negativas internalizadas organizam-se como um modelo básico para o estabelecimento de relações no mundo. Essas dificuldades emocionais relativas às experiências traumáticas se vinculam às representações mentais do objeto e do self, caracterizadas por imagens ambivalentes e dissociadas. Muitas vezes, essas representações negativas internalizadas continuam a causar distorções nas relações de adultos, percebidas subjetivamente de acordo com o modelo interno anterior negativo, com predomínio da identificação projetiva.

Pode-se observar, então, que as representações internas conflitivas e instáveis das figuras cuidadoras são mantidas como modelos de funcionamento que são reeditados nas relações adultas. Esse funcionamento se organiza em torno de características tais como inabilidade do agressor em manter um senso de estabilidade interna e bem-estar, baixa autoestima e fronteiras do self instáveis. Justamente essas características fazem com que, nas relações afetivas, os indivíduos procurem um parceiro que preencha ou que resolva essas necessidades internas (Zosky, 1999).

Esses estados afetivos resultam dos déficits ocorridos na infância que se reatualizam na relação conjugal. A violência ocorre, então, pelo temor da separação e da perda do amor do objeto, gerando no agressor o impulso de busca do poder como garantia contra o sentimento de dor pela separação do objeto. Ao contrário, os indivíduos que resolvem seus conflitos infantis de modo mais adequado, de acordo com Costa e Katz (1992), utilizam em menor amplitude o mecanismo da identificação projetiva, ressaltando que os cônjuges vão para o casamento com uma grande dose de independência e de possibilidade de enriquecerem-se uns aos outros e individualmente. Dessa forma, quando há resolução dos conflitos, as escolhas infantis de objeto podem ser substituídas por outras mais reais e atualizadas.

\section{Teoria do apego}

Outra vertente psicanalítica importante para a compreensão da violência nos vínculos interpessoais é a derivada da perspectiva da teoria do apego, originada nos trabalhos de Bowlby e Ainsworth. Inicialmente, Bowlby considerou o apego um mecanismo básico dos seres humanos, presente desde o embrião, que funciona como mecanismo de alimentação e da sexualidade, sendo considerado um sistema de controle homeostático, no qual as figuras de apego promovem e mantêm uma base de segurança frente a qualquer situação ameaçadora para o indivíduo. 
O termo apego, segundo o conceito de Ainsworth (1969), refere-se a um laço emocional que uma pessoa (ou animal) forma com outro indivíduo específico. As primeiras figuras de apego são os pais ou os cuidadores e, posteriormente, os amigos e os pares amorosos que podem representar as figuras iniciais de apego, que é uma disposição para buscar proximidade e contato com uma figura específica, sendo sua característica principal o estabelecimento do senso de segurança.

Para Bowlby (1984), o vínculo é uma ligação relativamente duradoura que se forma com um parceiro. É importante lembrar que ambos, tanto o vínculo afetivo como o apego, são estados internos. Os comportamentos de apego são observáveis e organizados nas interações das crianças com seus cuidadores, permitindo que a criança consiga obter e manter a proximidade. Mesmo quando o indivíduo estabelece um novo vínculo com um par sexual, não significa que o apego aos pais tenha desaparecido (Bowlby, 1989).

A partir da compreensão da dinâmica do apego, Ainsworth, Blehar, Waters e Wall (1978) e Main e Salomon (1990) sugeriram padrões para tipos de apego, fundamentados nas experiências dessas relações iniciais de apego. Ainsworth et al. (1990) identificaram três padrões de respostas do bebê à separação e à reunião com cuidadores: seguro, inseguro/ evitativo e inseguro/resistente.

A categoria estilo seguro de apego caracteriza as pessoas que recorrem ao ponto seguro de apoio das figuras de apego, quando se encontram em situações que remetem às perdas ou ao rompimento de laços afetivos. Elas voltam ao estado de tranquilidade ou de homeostase quando encontram essa figura de apego que as apoia, permitindo-lhes voltar-se para outros aspectos de seu interesse.
O estilo inseguro/evitativo caracteriza comportamentos em que não se procura o apoio das figuras de apego diante de situações estressantes pelo receio do afastamento dessas figuras ou dos laços de dependência; a atenção é dirigida para o campo externo, evitando o apego.

O estilo inseguro/resistente está relacionado ao comportamento de extremo estresse frente à separação das figuras de apego. Mesmo com o retorno do cuidador, há dificuldade de reestabelecer um estado de homeostase. Esses indivíduos são insatisfeitos e resistem a receber apoio, permanecendo ansiosos diante da possibilidade de nova ruptura do vínculo.

Main e Salomon (1990) acrescentam um quarto: o estilo desorganizado, que caracteriza a criança que não sabe de que forma voltar à situação de homeostase, apresentando respostas contraditórias frente à figura do apego, seja demonstrando interesse inicial por aproximação, o qual é seguido por agressão, seja por demonstrar desinteresse e pouca afetividade dirigida ao cuidador, por exemplo. Hesse e Main (2000) observam que crianças que apresentam esse tipo de apego podem desenvolver transtornos dissociativos na infância e na adolescência, enquanto adultos que apresentam esse estilo de apego aparecem frequentemente em populações psiquiátricas e penais.

Bowlby (1973) reconheceu que a raiva é a resposta natural da criança, quando a expectativa de segurança em relação à figura de apego está comprometida. No segundo ano, e talvez ainda mais cedo, as manifestações de raiva servem para manter a integridade do self representação. Entretanto, a persistência de situações que levam a respostas de raiva gera comportamentos defensivos agressivos, que passam a ser internalizados pela criança (Fonagy, 1999). 
Fonagy (1999) aponta que não é suficiente sustentar que o padrão de apego ansioso estaria na raiz do comportamento adulto violento.
No caso de homens agressores, pesquisas empíricas como as de Dutton (2002) demonstram que o temor de perda ou de separação do objeto é um dos grandes motivos da agressão conjugal. Esse autor observa que a raiva na relação interpessoal é decorrente da necessidade de apego frustrada, e funciona como uma forma de comportamento de protesto, que tem como objetivo reconquistar o contato com uma figura de apego.

Por sua vez, a frustração crônica na infância de necessidades de apego pode conduzir adultos a reagir com raiva extrema. Assim, a teoria do apego sugere que as explosões violentas no homem agressivo podem ser uma forma de comportamento de protesto dirigida a sua figura de apego (nesse caso, um parceiro sexual). Tanto Dutton (2002) como Hesse e Main (2000) associam agressividade e estilo de apego, sendo que o primeiro autor se reporta ao estilo desorganizado, e os outros dois, ao estilo inseguro.

Observa-se, portanto, que trabalhos contemporâneos sobre o vínculo agressivo trazem elementos integradores de conceitos psicanalíticos com a teoria do apego como base para entender o funcionamento psíquico do adulto. Nessa direção, Fonagy et al. (2002) introduzem uma importante aproximação entre a psicanálise e a teoria do apego, ressaltando que o conceito de mentalização é fundamental para entender o vínculo agressivo.

A mentalização é definida por Eizirik e Fonagy (2009) como uma atividade mental predominantemente pré-consciente que habilita a pessoa à compreensão de si própria e dos outros no que se refere aos processos mentais e aos estados subjetivos. Assim, os indivíduos que vivenciam uma infância traumática, defensivamente, são mais vulneráveis para a inibição dessa capacidade.
Dessa maneira, algumas características de homens violentos podem ser ligadas ao desenvolvimento de patologia associada a essa inibição. Falhas na capacidade de mentalização como fator desencadeante da agressão.

Fonagy et al.(2002) identificaram que as características vinculares nas situações de violência entre parceiros íntimos apresentam alguns aspectos específicos. Ampliando o entendimento dos comportamentos agressivos e violentos, Fonagy (1999) aponta que não é suficiente sustentar que o padrão de apego ansioso estaria na raiz do comportamento adulto violento. Nesse sentido, o autor expande a compreensão sobre as manifestações de violência, incluindo outra característica do vínculo estabelecido com as figuras cuidadoras iniciais, a qual se refere à incapacidade do cuidador em reconhecer e refletir o estado emocional da criança, falha que está no cerne do estabelecimento da subjetividade, do reconhecimento de si mesmo e da formação do self.

Portanto, a experiência de a criança sentir que existe na mente do cuidador é determinante da capacidade de reconhecer tanto a si mesmo (afetos, pensamentos) como aos demais, ou seja, da capacidade de pensar e de mentalizar. Traumas psicológicos nas fases iniciais da infância estão associados a prejuízos na capacidade de mentalização. Sobretudo, falhas importantes na capacidade de reconhecer estados internos subjetivos, tanto de si mesmo como dos demais, caracterizam o funcionamento de sujeitos com personalidade borderline (Fonagy, Target, \& Gergely, 2000).

A personalidade borderline possui características principalmente associadas à instabilidade afetiva, à impulsividade, à agressividade, à idealização ou à desvalorização dos relacionamentos, o que a 
torna um quadro clínico complexo associado ao risco de suicídio, ao abuso de substâncias e a outras formas de comportamento de risco. Critchfield, Levy, Clarkin e Kernberg (2008) consideram que o estilo de apego, nesses casos, é um dos elementos essenciais para o entendimento do funcionamento patológico, porque reflete o modelo de funcionamento interno fundado na representação do self e dos demais. Justamente, esse modelo de funcionamento interno construído desde os vínculos iniciais com as figuras parentais servirá de base para o desenvolvimento da identidade, da capacidade regulatória dos afetos e das experiências e da capacidade de manter proximidade com os demais. Nesse sentido, os autores destacam a importante associação entre o comportamento agressivo e o estilo de apego inseguro.

Indivíduos violentos têm sido identificados como aqueles que tiveram, na infância, experiências de abuso e de maus-tratos, as quais inibiram sua capacidade de mentalizar ou de representar os estados internos (do self e dos demais). Logo, nos relacionamentos violentos, quando ocorre a percepção de menor controle sobre o objeto em função de sua autonomia, desencadeia-se uma experiência que reativa o modelo de funcionamento interno associado ao medo e às experiências ansiosas, gerando a agressão e um retorno a um estado de pré-mentalização. Essa, por sua vez, restabelece o domínio sobre o objeto e a possibilidade de externalização desse self hostil (Fonagy, 1999).

Ambas as posturas teóricas discutidas acima tiveram implicações clínicas interessantes para o desenvolvimento de modelos de atendimento psicoterápicos que podem servir de referência para o trabalho psicanalítico de casos envolvidos com situações de violência. Destacam-se, em especial, o modelo da psicoterapia focada na transferência (Kernberg et al., 2008) e o da psicoterapia baseada na mentalização (Eizirik \& Fonagy, 2009).
A psicoterapia focada na transferência tem obtido bons resultados nos estudos randomizados nos casos de agressividade, suicídio, depressão e ansiedade (Silva, Yazigi, \& Fiore, 2008). A psicoterapia focada na transferência fundamenta-se na abordagem psicanalítica das relações de objeto, compreensão extensamente desenvolvida através dos trabalhos de Kernberg (Kernberg et al., 2008). Essa abordagem volta-se principalmente para o trabalho clínico, visando à integração dos aspectos polarizados das representações do self e dos demais, através de um setting mais estruturado e de intervenções baseadas na clarificação e na confrontação e em uma ênfase importante na vivência transferencial do aqui-e-agora da sessão terapêutica (Levy et al., 2006).

Desse modo, a estruturação do tratamento, a análise das dificuldades de forma clara e precisa e a compreensão da relação terapêutica que se estabelece na sessão determinam uma abordagem mais organizada voltada para a integração das representações do objeto e do self de forma mais coesa. Além disso, a postura do terapeuta é mais ativa e conscientemente atenta ao paciente, criando um setting caracterizado por experiências de continência dos afetos (holding) que por si só exercem efeitos terapêuticos importantes. Por último, a interpretação é dirigida aos temas trazidos para a sessão, apontando as dificuldades do paciente em reconhecer os estados afetivos presentes nas situações.

Outro modelo é o desenvolvido por Fonagy (Eizirik \& Fonagy, 2009), a psicoterapia baseada na mentalização, cujo foco é o desenvolvimento da capacidade de mentalização do paciente, a qual se dirige especialmente para o trabalho com indivíduos com personalidade borderline. $\mathrm{O}$ funcionamento borderline de personalidade pode ser entendido como a consequência de falha da mentalização e das capacidades 
associadas, tais como a representação, a regulação do afeto e o controle da atenção. Prevalecem, dessa maneira, formas primitivas de subjetividade e uma desorganização profunda da estrutura do self. A fenomenologia do transtorno de personalidade borderline pode ser conceituada como a consequência de três aspectos: um estilo de apego associado à inibição da mentalização, a revivência de modos de experienciar a realidade interna anteriores ao desenvolvimento da capacidade de mentalização e experiências de pressão constante para a utilização de defesas de identificação projetiva do self destrutivo no outro. Nessa ótica, Eizirik e Fonagy consideram que recuperar a mentalização no contexto das relações vinculares é um mecanismo básico de muitos tratamentos psicossociais para a desordem de personalidade borderline.

\section{Considerações finais}

Iniciamos este artigo destacando a importância do estudo aprofundado do comportamento violento sob a perspectiva psicanalítica. Observamos que a teoria psicanalítica pode oferecer subsídios importantes para uma adequada avaliação e, em consequência, um planejamento interventivo, levando-se em conta as características intrapsíquicas de cada sujeito. Nesse sentido, destaca-se que, partindo de um modelo freudiano inicial sobre a agressão humana, autores como Kernberg e Fonagy ampliaram a compreensão dos diversos elementos envolvidos na violência e na agressão, possibilitando um entendimento mais aprofundado e também uma intervenção mais sensível para esses casos.

Além disso, alguns estudos também têm apontado carências e necessidades importantes de ações dirigidas para a melhoria das intervenções relativas aos casos de violência doméstica. Considerando que o atendimento ao agressor também é uma etapa necessária no combate à violência doméstica, principalmente levando em conta as relações familiares e especificamente o vínculo com os filhos, consideramos que esta revisão abra a possibilidade de novas pesquisas para a promoção de ações voltadas para a questão da violência, visando a qualificar o trabalho realizado e a desenvolver ações de intervenção conjuntas e qualificadas que sustentem metas preventivas à violência. 


\section{Suzana Catanio dos Santos Nardi}

Mestre em Psicologia pela Universidade do Vale do Rio dos Sinos e professora convidada do curso MBA Gestão do Comportamento Organizacional da Universidade do Vale do Rio dos Sinos, São Leopoldo - RS - Brasil.

E-mail: suzanacatanio@hotmail.com

\section{Silvia Pereira da Cruz Benetti}

Doutora em Child and Family Studies - Syracuse University e Professora Adjunta no Programa de Pós-Graduação em Psicologia da Universidade do Vale do Rio dos Sinos, São Leopoldo - RS - Brasil.

E-mail: sbenetti@unisinos.br

\section{Endereço para envio de correspondência:}

Rua Villa Lobos, 647, Bairro Tamandaré. CEP: 93260-400. Esteio, RS.

Recebido 26/08/2011, 1a Reformulação 11/06/2013, Aprovado 29/08/2013

\section{Referências}

Ainsworth, M. D. S. (1969). Object relations, dependency, and attachment: A theoretical review of the infant-mother relationship. Child Development, 40, 969-1025.

Ainsworth, M. D. S., Blehar, M. C., Waters, E., \& Wall, S. (1978). Patterns of attachment: A psychological study of the strange situation. Hillsdale, New Jersey: Erlbaum.

Bowlby, J. (1973). Attachment and loss (Vol 2). Separation, anxiety and anger. London: Hogarth Press.

Bowlby, J. (1984). Apego. São Paulo: Martins Fontes.

Bowlby, J. (1989). Uma base segura: aplicações clínicas da teoria do apego. Porto Alegre: Artes Médicas.

Bowlby, J. (1990). Apego e perda (Vol I). Apego. São Paulo: Martins Fontes (Trabalho original publicado em 1969).

Bruscato, W. (1998). Tradução, validade e confiabilidade de um inventário de avaliação de relações objetais (BORRTI-Forma O). Dissertação de mestrado. Escola Paulista de Medicina, Universidade Federal de São Paulo, SP.

Cogan, R., \& Porcerelli, J. H. (1996). Object relations in abusive partner relationships: An empirical investigation. Journal of Personality Assessment, 66, 106-115.

Cogan, R., Porcerelli, J. H., \& Dromgoole, K. (2001). Psychodynamics of partner, stranger, and generally violent male college students. Psychoanalytic Psychology, 18, 515-533.
Costa, G. P., \& Katz, G. (1992). Dinâmica das relações conjugais. Porto Alegre: Artes Médicas.

Critchfield, K. L., Levy, K. N., Clarkin, J. F., \& Kernberg, O. F. (2008). The relational context of aggression in borderline personality disorder: Using adult attachment style to predict forms of hostility. Journal of Clinical Psychology, 64(1), 67-82.

Diamond, D. (2004). Attachment disorganization: The reunion of attachment theory and psychoanalysis. Psychoanalytic Psychology, 21, 276-299.

Dutton, D. (2002). Personality dynamics of intimate abusiveness. Journal of Psychiatric Practice, 8, 216-228.

Eizirik, M., \& Fonagy, P. (2009). Terapia de mentalização para pacientes com transtorno de personalidade borderline: uma atualização. Revista Brasileira de Psiquiatria, 31(1), 72-75.

Ferenczi, S. (1992). Confusão de língua entre os adultos e a criança. In S. Ferenczi. Obras completas (A. Cabral trad.,.Vol. 4, pp. 97-108). São Paulo: Martins Fontes (Trabalho original publicado em 1933).

Ferrari, I. F. (2006). Agressividade e violência. Psicologia Clínica, 18(2), 49-62.

Fonagy, P. (1999). Male perpetrators of violence against women: An attachment theory perspective. Journal of Applied Psychoanalytic Studies, 1, 7-27.

Fonagy, P., Target, M., \& Gergely, G. (2000). Attachment and 
borderline personality disorder. A theory and some evidence. The psychiatric clinics of North America, 23, 103-122.

Fonagy, P., Gergely, G., Jurist, E., \& Target, M. (2002). Affect regulation, mentalization and the development of the self. New York: Other Press.

Freud, S. (1976). Além do princípio do prazer. In Edição standard brasileira das obras psicológicas completas de Sigmund Freud (J. Salomão trad., Vol. 18, pp. 17-90). Rio de Janeiro: Imago (Trabalho original publicado em 1920).

Freud, S. (1976). O problema econômico do masoquismo. In Edição standard brasileira das obras psicológicas completas de Sigmund Freud (J. Salomão trad.,Vol. 19, pp. 199-216). Rio de Janeiro: Imago (Trabalho original publicado em 1924).

Freud, S. (1976). Totem e tabu. In Edição standard brasileira das obras psicológicas completas de Sigmund Freud (J. Salomão trad,.Vol. 13, pp.17-192). Rio de Janeiro: Imago (Trabalho original publicado em 1913).

Freud, S. (1996). Uma criança é espancada. Uma contribuição ao estudo da origem das perversões sexuais. In Edição standard brasileira das obras psicológicas completas de Sigmund Freud (J. Salomão trad., Vol. 17, pp. 225-258). Rio de Janeiro: Imago (Trabalho original publicado em 1919).

Freud, S. (1996). O instinto e suas vicissitudes. In Edição standard brasileira das obras psicológicas completas de Sigmund Freud (J. Salomão trad.,.Vol. 14, pp. 137-168). Rio de Janeiro: Imago (Trabalho original publicado em 1915).

Freud, S. (1996). Sobre o narcisismo: uma introdução. In Edição standard brasileira das obras psicológicas completas de Sigmund Freud (J. Salomão trad.,.Vol. 14, pp. 77-108). Rio de Janeiro: Imago (Trabalho original publicado em 1914).

Freud, S. (1996). Três ensaios sobre a teoria da sexualidade. In Edição standard brasileira das obras psicológicas completas de Sigmund Freud (J. Salomão trad.,.Vol. 7, pp. 129-238). Rio de Janeiro: Imago (Trabalho original publicado em 1905).

Freud, S. (1996). O mal-estar na civilização. In Edição standard brasileira das obras psicológicas completas de Sigmund Freud (J. Salomão trad.,Vol. 21, pp. 81-178). Rio de Janeiro: Imago (Trabalho original publicado em 1930).

Hesse, E., \& Main, M. (2000). Disorganized infant, child, and adult attachment: Collapse in behavioral and attentional strategies. Journal of the American Psychoanalytic Association, 48, 1097-1127.

Kernberg, O. F. (1979). La transferencia y la contratransferencia en el tratamiento de pacientes fronterizos. In O. F. Kernberg (Org.), La teoria de las relaciones objetales y el psicoanálisis clínico. Buenos Aires: Paidós.

Kernberg, O. F. (1995). Agressão nos transtornos de personalidade e nas perversões. Porto Alegre: Artes Médicas.

Kernberg, O. (2002). Transference focused psychotherapy for borderline patients. Recuperado em 25 de maio de 2011 de Psy Broadcasting Corporation. http://www.psybc.com/paperinfo.php?paper_id $=121$

Kernberg, O. F., Yeomans, F. E., Clarkin, J. F., \& Levy, K. N. (2008). Transference focused psychotherapy. Overview and Update
International Journal Psychoanalysis, 8, 601-620.

Klein, M. (1969). Os progressos da psicanálise. Rio de Janeiro: Zahar (Trabalho original publicado em 1932).

Kronbauer, J. F. D., \& Meneghel, S. N. (2005). Perfil da violência de gênero perpetrada por companheiro. Revista de Saúde Pública, 39(5), 695-701.

Lamanno-Adamo, V. L. C. (1999). Violência doméstica: uma contribuição da psicanálise. Ciências \& Saúde Coletiva, 4, 159-159.

Laplanche, J., \& Pontalis, J. B. (2001). Vocabulário de psicanálise (4a ed.). São Paulo: Martins Fontes.

Levy, K. N., Clarkin, J. F., Yeomans, F. E., Scott, L., Wasserman, R., \& Kernberg, O. F. (2006). The mechanisms of change in the treatment of borderline personality disorder with transference focused psychotherapy. Journal of Clinical Psychology, 62, 481-501.

Maciel, R. A., \& Rosemburg, C. P. (2006). A relação mãe-bebê e a estruturação da personalidade. Saúde e Sociedade, 15(2), 96-112.

Main, M., \& Solomon, J. (1990). Procedures for identifying infants as disorganized/disoriented during the Ainsworth strange situation. In M. T. Greenberg, D. Cicchetti \& E. M. Cummings (Orgs.), Attachment in the preschool years (pp. 121-160). Chicago: University of Chicago Press.

Moore, B. E., \& Fine, B. D. (1990). Psychoanalytic terms and concepts. New Haven: The American Psychoanalytic Association.

Nigg, J. T., Silk, K. R., Westen, D., Lohr, N. E., Gold, L. J., Goodrich, S., \& Ogata, S. (1991). Object representations in the early memories of sexually abused borderline patients. The American Journal of Psychiatry, 148, 864-869.

Saffioti, H. I. B. (2001). Contribuições feministas para o estudo da violência de gênero. Cadernos Pagu, 16, 115-136.

Schmidt-Hellerau, C. (2002). Why aggression? Metapsychological, clinical and technical considerations. The International Journal of Psychoanalysis, 83(6), 1269-1289.

Silva, J. F. R., Yazigi, L., \& Fiore, M. L. M. (2008). Psicanálise e universidade: a interface possível por meio da pesquisa psicanalítica clínica. Alice quebra-vidros. Revista Brasileira de Psiquiatria, 30(2), 152-155.

Winnicott, D. (1999). Tudo começa em casa. São Paulo: Martins Fontes (Trabalho original publicado em 1967).

Zosky, D. L. (1999). The application of object relations. Theory to domestic violence. Clinical Social Work Journal, 27(1), 55-69. 